This item was submitted to Loughborough's Research Repository by the author.

Items in Figshare are protected by copyright, with all rights reserved, unless otherwise indicated.

\title{
Comprehensive design method for earthbag and superadobe structures
}

\section{PLEASE CITE THE PUBLISHED VERSION}

https://doi.org/10.1016/j.matdes.2016.02.028

\section{PUBLISHER}

(c) Elsevier

\section{VERSION}

AM (Accepted Manuscript)

\section{PUBLISHER STATEMENT}

This work is made available according to the conditions of the Creative Commons Attribution-NonCommercialNoDerivatives 4.0 International (CC BY-NC-ND 4.0) licence. Full details of this licence are available at: https://creativecommons.org/licenses/by-nc-nd/4.0/

\section{LICENCE}

CC BY-NC-ND 4.0

\section{REPOSITORY RECORD}

Canadell, Samuel, Ana Blanco-Alvarez, and Sergio Pialarissi-Cavalaro. 2016. "Comprehensive Design Method for Earthbag and Superadobe Structures". Loughborough University. https://hdl.handle.net/2134/32294. 


\title{
1 Comprehensive design method for earthbag and superadobe structures
}

3 Samuel Canadell ${ }^{\mathrm{a}}$, Ana Blanco ${ }^{\mathrm{a}}$, Sergio H. P. Cavalaro ${ }^{\mathrm{a}^{*}}$

4

5

6

7 Barcelona, Spain

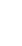

Keywords: earthbag; superadobe; design method; wall; dome; finite element

${ }^{a}$ Department of Civil and Environmental Engineering, Universitat Politècnica de Catalunya, UPC, Jordi Girona 1-3, 08034

* Corresponding author. Tel.: +34-93-405-4247; fax:+34-93-401-1036; e-mail: sergio.pialarissi@upc.edu

\begin{abstract}
The earthbag and superadobe techniques consist of introducing soil in degradable bags that are stacked to form adobe structures. They represent sustainable, rapid and low-cost alternatives for the construction of social housing, emergency shelter and ecovillages with the resources available at each location. Despite their potential, several aspects still compromise the efficient and safe use of these techniques. For instance, the design of the structures is currently based on empirical or semi-empirical guidelines since no general method exists on the matter. The present work focuses on the proposal of simple, comprehensive and rational design method for earthbag and superadobe walls and domes. Formulations are proposed considering the previous studies from the literature. Parametric studies are conducted in order to evaluate the influence of several geometrical and mechanical variables on the response and safety of the structures built with this technique. The design method is then evaluated numerically through a finite element analysis. The developments derived from this study represent a contribution towards the safe and optimized design of earthbag and superadobe structures, being a valuable guide for future construction.
\end{abstract}


In emergency situations (such as humanitarian crisis, wars or hazardous natural events) it is essential to provide the population affected with safe and secure shelter, quickly and at low costs. Among the possible materials for the construction of such shelters, the most abundant regardless of the location is the earth or soil available in the environment. In this context, the construction techniques of the earthbag and the superadobe were developed.

These techniques consist of introducing local soil and small amounts of a binder in degradable bags that serve as the formwork and as confinement of the filling. The bags are stacked one over the other forming the walls of the house. The earthbag technique uses regular bags to contain the soil, whereas the superadobe employs long bags as shown in Fig.1. The adherence and friction between rows is improved by placing barbwire on top of each row. Once the bags are filled, they are slightly compressed to remove the air inside the bag and to regularise the contact surface. This allows the construction of walls and domes, as shown in Fig. 1. The technique has been extensively applied in emergency situations in Africa and South America, showing benefits in terms of acoustic and thermal insulation properties (Teslik and Vodicková 2014, Zhao et al. 2015).

61
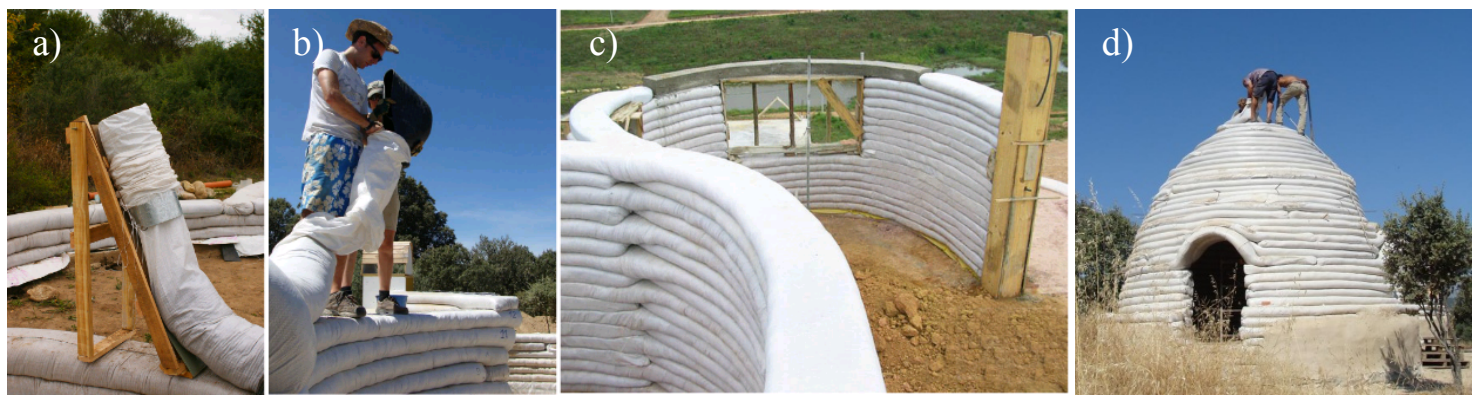

Fig. 1 - Construction of superadobe structures (sources: www.labioguia.com (a), www.domoterra.es (b,

d), www.earthbagbuilding.com (c))

This construction technique has spread in the past 25 years since its creation by the Iranian architect Nader Khalili, who proposed fundamental rules for the design and building recommendations (Khalili 1986). Khalili was also the founder of Cal-Earth Institute in the United States (US) that promotes the development and research on earth structures. Experimental studies regarding structures under static and dynamic loads were conducted in order to evaluate the global stability and the earthquake response (Khalili and Vittore 1998). Based on the results obtained, the superadobe was recognized as a building technique in California with some restriction of the maximum dimensions of the structures. In the past 10 years, research has also been conducted on the compressive (Daigle 2008, Pelly 2010, Croft 
2011) and shear (Vadgama 2010, Croft 2011) behaviour of earthbag piles or walls, providing experimental data about the material and the structure.

Despite the advances attained, the design is still based on empirical or semi-empirical rules (Minke 2001, Wojciechowska 2001, Hunter and Kiffmeyer 2004, Geiger 2011). Even though several countries such as the US (ASTM 2010), Brazil (ABNT 1998) and Spain (AENOR 2008, Cid et al. 2011) include the soil as a building material in the form of adobe or mud walls, the earthbag technique (combined behaviour of the earth and the bag with joints) is not contemplated in the standards due to the lack of theoretical models for the design of structures and testing methods for the characterization of the material.

Generally, no structural analysis is conducted prior to building. In the cases that calculations are performed, the design is restricted to the study of the roll-over stability and the collapse of the superadobe under the hypothesis that the domes work monolithically. Cross-sections are assumed capable of bearing tangential and normal (both compressive and tensile) stresses, which is not completely true in the case of superadobe domes since joints between bags introduce a special structural behavior. Moreover, geometric variations, material properties, environmental conditions and other boundary conditions are hardly ever taken into account. This scenario may lead to either an overestimated or an unsafe design of structures, which contrasts with the sustainable philosophy grounded on the efficient use of the resources and raw materials associated with the technique.

The objective of this study is to propose a simple, comprehensive and rational design method for earthbag and superadobe structures that enables an efficient use of the resources and raw materials available in the environment and ensures the construction of safe structures. The simplicity is considered paramount here since the method should be easily implemented, even without advanced computational tools that might not be available in extreme conditions or isolated locations where the technique should be applied. The proposal of the design method is made separately for the walls and for the domes, accounting for possible combinations between them. Based on previous experimental and numerical studies from the literature, the main failure and resistant mechanisms are first identified. A simplified procedure to verify the resistant capacity of the earthbag walls and domes with safety margins is proposed. Then, the influence of several geometric and mechanical variables on the structural response is ascertained through a parametric study that allows determining critical parameters for the design. The simplified method is also numerically validated by means of a finite element analysis and compared with other alternative approaches from the literature.

The present study contributes to increase the knowledge on the earthbag and superadobe techniques by presenting a first step towards a general design method valid for earthbag or superadobe structures. The rational approach ensures the structural safety and the optimization of the material, thus enhancing its sustainability and setting the basis for future design 
112 recommendations or codes. Besides being a valuable guide from an engineering standpoint, this

113 study might have a positive social impact in emergency and humanitarian crisis situations.

\section{TYPICAL SUPERADOBE STRUCTURE}

117 Superadobe structures may present a rectangular plant with straight walls or a round plant with 118 walls that provide support to a dome. Walls are usually built with bags ranging from 0.30 to $1190.40 \mathrm{~m}$ wide that are piled up to a height of $2.5 \mathrm{~m}$. The dome is usually formed by piling 120 consecutive rows of bags with a perimeter that reduces with the height.

121 Fig. 2a shows a typical vertical cross section of a superadobe construction composed by dome, 122 wall, buttress and foundation. The buttress is an external containing wall used when high 123 horizontal forces are applied. The foundations provide support to the structure, consisting of a 124 minimum of 3 rows below the ground level that transmit the horizontal and vertical forces to the ground. In case the properties of the soil do not meet the load requirements, the number of rows in the foundations may be increased.
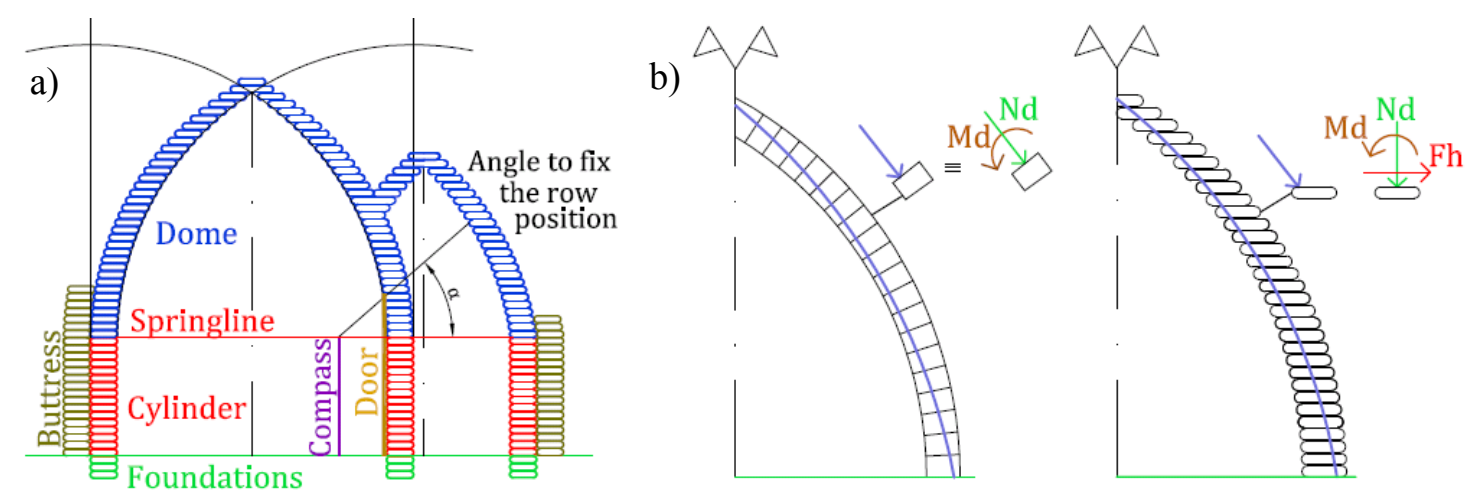

Fig. 2 - Cross section of a dome house (a) conventional and superadobe domes differences (b)

The inner diameter of the dome may range between $3.5 \mathrm{~m}$ and $5.0 \mathrm{~m}$. In earthbag or superadobe construction, it is possible to connect several domes with the aim of dividing the inner spaces as shown in Fig. 2a. Moreover, openings are also introduced to generate place for doors and windows. Wood, concrete or steel beams are installed above the openings to redirect the loads around them since the earthbags do not provide enough stiffness at early stages.

136 Studies from the literature analysed different properties of the material (Lohani et al. 2006,

137 Daigle 2008, Pelly 2010, Vadgama 2010 and Croft 2011). In particular, Croft (2011) performed 138 laboratory tests of earthbag piles to evaluate the tensile strength $\left(T_{b a g}\right)$ and a tearing resistance $139\left(T_{\text {tear }}\right)$ of the bag. Moreover, Vadgama (2010) conducted tests to evaluate the behaviour of the 140 earthbag joints with barbed wire between rows. The author demonstrates that the inclusion of 141 the barbed wire increases the cohesion $\left(C_{b w}\right)$ and the static friction coefficient $\left(\mu_{\text {bags }}\right)$ of the 
contact between bags. Although the properties depend on the characteristics of the bag and adobe used, typical values reported by those authors are summarized in Table 1. Notice that no value of the tensile yield stress of the adobe $\left(f_{\text {adobe, }, t}\right)$ is provided in the studies. This value is generally assumed as $1 \%$ of the compressive yield stress of the adobe $\left(f_{\text {adobe }}\right)$.

Table 1 - Material properties

\begin{tabular}{ccc}
\hline Parameter & Value & Reference \\
\hline$T_{\text {bag }}$ & $10 \mathrm{kN} / \mathrm{m}$ & Croft (2011) \\
$T_{\text {tear }}$ & $0.14 \mathrm{kN}$ & Croft (2011) \\
$C_{b w}$ & $5.50 \mathrm{kN} / \mathrm{m}^{2}$ & Vadgama (2010) \\
$\mu_{\text {bags }}$ & 0.67 & Vadgama (2010) \\
$f_{\text {adobe }}$ & $2000 \mathrm{kN} / \mathrm{m}^{2}$ & Robin et al. (2015) \\
\hline
\end{tabular}

An important difference between conventional domes and superadobe or earthbag domes is the angle formed between the centreline of the structure and the joint surface, as depicted in Fig. $2 b$. In the case of conventional domes, joints are usually perpendicular to the centreline, which tends to increase stresses normal to this surface. Consequently, shear stresses are reduced and the shear strength of the joint is increased. On the contrary, in the case of superadobe domes, the centreline is inclined regarding the joint surface, leading to a reduction of the normal stresses and an increase of the tangential stresses. This intensifies the risk of failure of the joint, whose behaviour should be carefully verified.

The method proposed here applies to the design of earthbag and superadobe walls and domes, taking into account the special behaviour of the joints as well as the discontinuity introduced by openings. As in other methodologies for the design of dome-like structures, some simplifications are assumed. Specific calculations with more accurate tools should be performed in complex structures or in structures subjected to unusual boundary conditions.

\section{SUPERADOBE WALLS}

This section focuses on the design of superadobe walls. First, the basis for the structural verification is set. Then, a parametric study is conducted considering different geometries and material properties.

\subsection{Stresses and structural verification}

The walls usually receive forces at the top - observed especially in case it gives support to a dome or to other covering element. The external resultant force $\left(F_{d}\right)$ may be applied as indicate in Fig. 3a. 


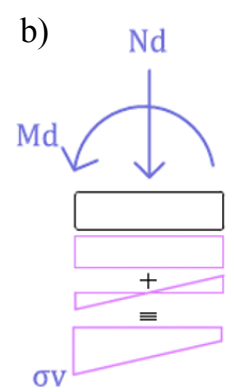

c)

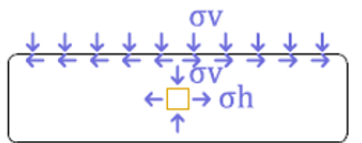

Fig. 3 - Forces $N_{d}, T_{d}$ and $M_{d}$ acting on the wall (a), combined bending and axial compression in a row (b), stresses in a bag under vertical loading (c)

$F_{d}$ is equivalent to a normal component $\left(N_{d}\right)$, an horizontal component $\left(T_{d}\right)$ and a bending force $\left(M_{d}\right)$ due to the eccentricity. The normal force applied in each interface increases in lower bags as the weight of the upper part of the wall increases. The horizontal forces and the bending moment vary due to the effect of lateral loading, such as wind forces $\left(W_{d}\right)$. Fig. $3 \mathrm{~b}$ shows the combined application of bending and axial forces in a row, which produce a non-uniform stress distribution in the interface. Notice that the application of the normal stresses should also induce tangential stresses because of to the lateral confinement created by the bag, as shown in Fig. 3c. To simplify the description of the formulations, all variables are described in the list of symbols. In general, the letter $i$ is appended as a subscript to the variables in order to make reference to the calculation at a certain earthbag row. In case the letter $i$ do not appear as a subscript, the variable makes reference to the global analysis of the wall, considering the boundary conditions. The resistant and failure mechanisms of the wall are determined by considering the design values of the forces $\left(N_{d}, T_{d}, M_{d}, W_{d}\right)$ and of the stresses. In order to guarantee the structural safety, the design value of the strength $\left(S_{d}\right)$ should be bigger than or equal to the stresses generated by the actions $\left(A_{d}\right)$. In other words, the safety factor $(S F)$ shown in Eq.1 should be bigger than 1 .

$$
S F=S_{d} / A_{d}
$$

Vertical stresses generate a horizontal component to the bag due to the lateral earth pressure of the soil when subjected to normal loads. The bag is responsible for resisting these stresses (Tantono 2007, Pelly 2010, Vadgama 2010), which may be calculated as indicated in Eq.2 and Eq. 3 for the row $i$.

$$
\sigma_{d, v, i}=\frac{N_{d, i}}{b L}+\frac{6\left(M_{d, i}+T_{d, i} z_{i}\right)}{b^{2} L}
$$




$$
\frac{\sigma_{d, v, i}}{\sigma_{d, h, i}}=K_{p}
$$

202

203

204

205

206

207

208

209

210

211

212

213

214

215

216

217

218

219

220

221

222

223

224

225

226

227

228

229

230

Taking the expression above, the global stability of the wall and the local stability of each bag or joint have to be verified. Table 2 shows the equations that were deducted based on the principles of material and structural mechanics for the verification of the possible failure mechanisms that might occur considering the specificities of superadobe walls.

Table 2 - Equations for structural verifications in walls

\begin{tabular}{l|cc}
\hline \multicolumn{1}{c|}{ Mechanism } & Verification \\
\hline Collapse (Fig. 4a) & $f_{\text {ground }} \geq \sigma_{d, v, 1}$ \\
\hline Buckling (Fig. 4b) & $\pi^{2} b^{3} L E_{\text {adobe }} /\left(48 H^{2}\right) \geq N_{d, \text { max }}$ & (Eq.4) \\
\hline Roll-over (Fig. 4c) & $N_{d, i} b / 2 \geq M_{d, i}+T_{d, i} h$ \\
\hline Slipping (Fig. 4d) & $c_{b w} b L+N_{k, i} \mu \geq T_{d, i}$ \\
\hline Tear of the bag (Fig. 4e) & $T_{\text {tear }} \geq T_{d, i}-N_{d, i} \mu$ \\
\hline Failure of the adobe (Fig. $4 f)$ & $f_{a d o b e} \geq \sigma_{d, v, i}$ \\
\hline Failure of the bag (Fig. 4g) & $2 K_{p} T_{b a g} / h \geq \sigma_{d, v, i}$ \\
\hline
\end{tabular}

As indicated in Table 2, several conditions have to be simultaneously satisfied in order to avoid the global or the local collapse of the structure.

- Collapse of foundation: The ground strength $\left(f_{\text {ground }}\right)$ must be larger than the vertical stresses at the bottom row of the pile (see Eq.4).

- Buckling of the structure: The maximum axial force should be smaller than the critical load obtained according with Euler's formulation for a simply supported element (see Eq.5).

- Roll-over: The destabilizing bending forces should be smaller than the stabilizing ones (see Eq.6).

- Slipping of the bags: The tangential force should be smaller than the resistance of the interface, which was assessed using a Coulomb Friction model using the cohesion and the static friction of the interface (see Eq.7).

- Tear of the bag: The tear strength should be larger than the tangential force minus the static friction (see Eq.8).

- Failure of the adobe and the bag: The vertical stresses must be smaller than the adobe yield stress and the bag yield stress multiplied by the coefficient of lateral earth pressure (see Eq. 9 and 10, respectively).

The graphic representation of the each failure mechanism is depicted in Fig.4. Notice that the strength of the materials corresponds to the age of the material at the moment of conducting the verifications. This is especially relevant in case a binder is used in combination with the soil. Usually, the most critical situation in terms of resistant capacity takes place just after the 
231 construction, before the bags have degraded and an improved connection develops between the 232 materials from different rows.

233

234

235

236

237

238

239

240

241

242

243

244

245

246

247

248

249

250

251

252

253

254

255

256

257

258

259 a) $\mid \mathrm{Nd} \quad$ b) $\mid \mathrm{Nd} \quad$ c) $\mathrm{Fd} \quad$ d)

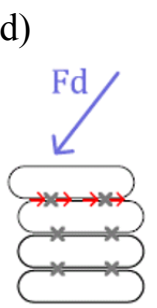

e)

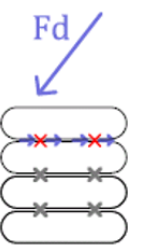

f)

g)

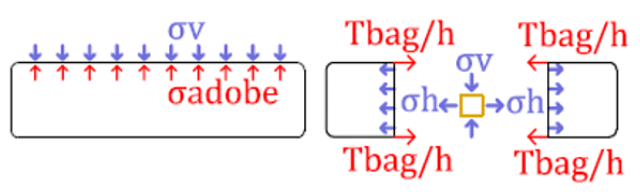

Fig. 4 - Possible failure mechanisms: global collapse (a), buckling (b), roll-over (c), local slipping (d), tear of the bag (e), adobe failure (f) and bag failure ( $g$ )

\subsection{Parametric study}

A parametric study was conducted to analyze the influence of geometric and design variables in the structural response. In practice, the boundary conditions, the geometries and the material properties may vary considerably depending on each location. The selection of parameters and their ranges was based on values reported in other studies from the literature and previous experiences by the authors. The main idea was to cover the typical cases of superadobe structures found in practice. Table 3 shows the parameters considered for the study and their values. In particular, the values regarding the mechanical properties were chosen from studies in the literature (Daigle 2008, Pelly 2010, Vadgama 2010, Croft 2011) and the range of design forces is roughly estimated assuming the weight of the roofing, the live load as well as the wind and snow loads. The dimensions of the walls were defined based on the common values appearing in superadobe projects and buildings (Khalili 1986, Hunter 2004, Geiger 2011).

Table 3 - Geometric and material properties for the parametric study of the walls

\begin{tabular}{|c|c|c|c|c|c|c|c|c|c|c|c|c|c|}
\hline $\begin{array}{c}N_{d} \\
(k N)\end{array}$ & $\begin{array}{c}T_{d} \\
(k N)\end{array}$ & $\begin{array}{c}M_{d} \\
(k N m)\end{array}$ & $\begin{array}{c}B \\
(m)\end{array}$ & $\begin{array}{c}H \\
(m)\end{array}$ & $\begin{array}{c}D \\
\left(k N / m^{3}\right)\end{array}$ & $\begin{array}{l}K \\
(-)\end{array}$ & $\begin{array}{c}E_{\text {adobe }} \\
\left(\mathrm{kN} / \mathrm{m}^{2}\right)\end{array}$ & $\begin{array}{c}f_{\text {adobe }} \\
\left(\mathbf{k N} / \mathbf{m}^{2}\right)\end{array}$ & $\begin{array}{c}f_{\text {ground }} \\
\left(\mathrm{kN} / \mathrm{m}^{2}\right)\end{array}$ & $\begin{array}{c}T_{b a g} \\
(\mathrm{kN} / \mathbf{m})\end{array}$ & $\begin{array}{l}T_{\text {tear }} \\
(k N)\end{array}$ & $\begin{array}{c}C_{b w} \\
\left(\mathrm{kN} / \mathrm{m}^{2}\right)\end{array}$ & $\begin{array}{r}\mu_{b a g} . \\
(-)\end{array}$ \\
\hline 1 & 0 & & 0.25 & 0.50 & & & & & & & & & \\
\hline to & to & $0.06 \mathrm{~N}_{\mathrm{d}}$ & to & to & 19 & 2.40 & 10000 & 2000 & 200 & 10 & 0.14 & 5.50 & 0.67 \\
\hline 15 & 2 & & 0.45 & 2.50 & & & & & & & & & \\
\hline
\end{tabular}

\subsubsection{Parameters influence in the structural safety}

The analysis in this section focuses on the influence of the parameters studied in the critical verification of all equations presented in Table 1 . Three load cases are considered for the variation of the design forces: the axial force varies and the shear force is zero; an axial force of 
$26010 \mathrm{kN}$ and only the shear force varies; both parameters vary but the ratio $N_{d} / T_{d}$ remains constant

261 in all cases. The safety factor was calculated for each failure mode in accordance with Eq.1.

262 The smallest $S F$ obtained for different width of the bag $(B)$ and a height of $2.5 \mathrm{~m}$ are presented

263 in Fig.5a, 5b and 5c. In this figure, the vertical axis corresponds to the structural $S F$ and the

264 horizontal axis depicts the values of the parameter studied. Notice that a value equal or lower

265 than 1 in the vertical axis indicates that at least one verification is not satisfied. This limit is

266 depicted as a red continuous line in all graphs. The predominant failure mode is also indicated

267 by the type of marker used in each curve.

268 Fig. $5 \mathrm{a}, 5 \mathrm{~b}$ and $5 \mathrm{c}$ reveal that $B$ is a key parameter regarding the structural safety. To achieve $S F$

269 bigger than $1, B$ bigger than 0.35 is needed in practically all scenarios simulated in this

270 parametric study. As expected, the influence of $B$ is highly sensible to the normal action at the

271 top of the wall $\left(N_{d}\right)$. The variation in the $S F$ as a result of modifications of the tangential action

$272\left(T_{d}\right)$ is considerably smaller for the typical range found in practice. This is reasonable since the

273 most likely failure modes are due to buckling and to roll-over of the wall, both of which depend

274 mainly of the area of the cross section of the wall and of the normal actions.

275 Interestingly, as the normal forces decreases and the width increases, the critical condition tends

276 to be related with other boundary conditions and the predominant failure mode changes. As

277 observed in Fig. 5a and 5c, for the cases with $N_{d}$ of 1 and B bigger than $0.3 \mathrm{~m}$, the smallest $S F$

278 occurs for the collapse verification. The latter, is closely related with the ground mechanical

279 properties. Other parameters such as the compressive strength of the adobe $\left(f_{\text {adobe }}\right)$, the tensile

280 strength of the bag $\left(T_{b a g}\right)$, the contribution of the barbed wire $\left(C_{b w}\right)$ or the friction coefficient

281 between bags do not have any influence in this case of study since they are not related with

282 failure due to global or local roll-over nor buckling.

283 Another important variable during the design process is the height of the structure $(H)$. The

284 influence of this parameter on the structural safety is presented in Fig. 5d, 5e and 5f for a

285 constant $B$ of $0.45 \mathrm{~m}$. Again, different conditions in terms of $N_{d}$ and $T_{d}$ are considered. In

286 general, the increase of $H$ leads to a reduction of the $S F$. The exception is observed when the

287 predominant failure is due to roll-over and low normal forces are applied. In this case, the

288 increase of height produces an increase of the compressions at the base of the column. Such

289 compressions stabilize the wall and reduce the risk of failure due to roll-over, thus increasing

290 the $S F$. As a higher $N_{d}$ is applied, the failure becomes governed by the collapse or the buckling,

291 which are negatively influenced by the increase of $H$. Consequently, a decrease of the $S F$ is observed with the increase in $H$. 

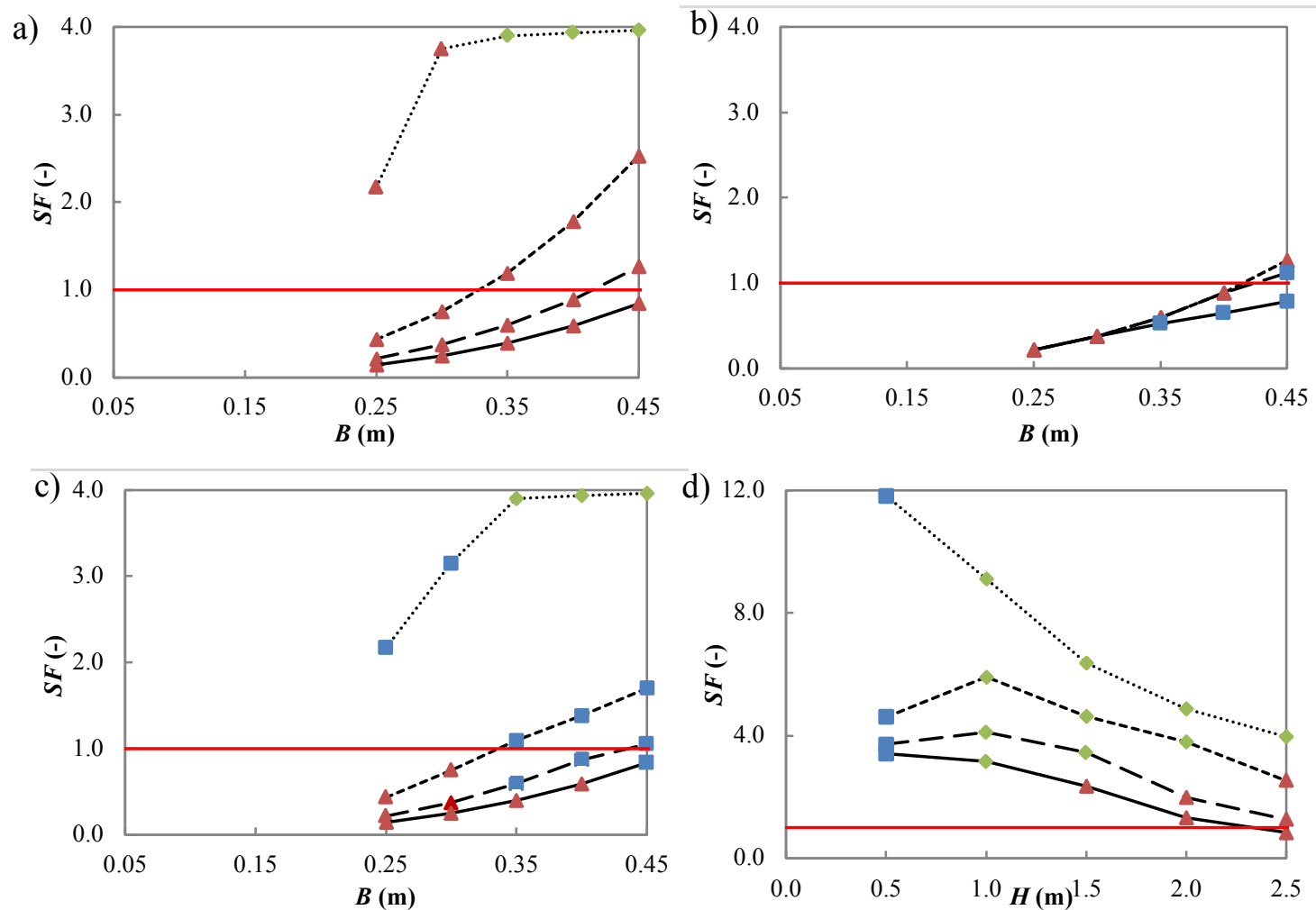

295
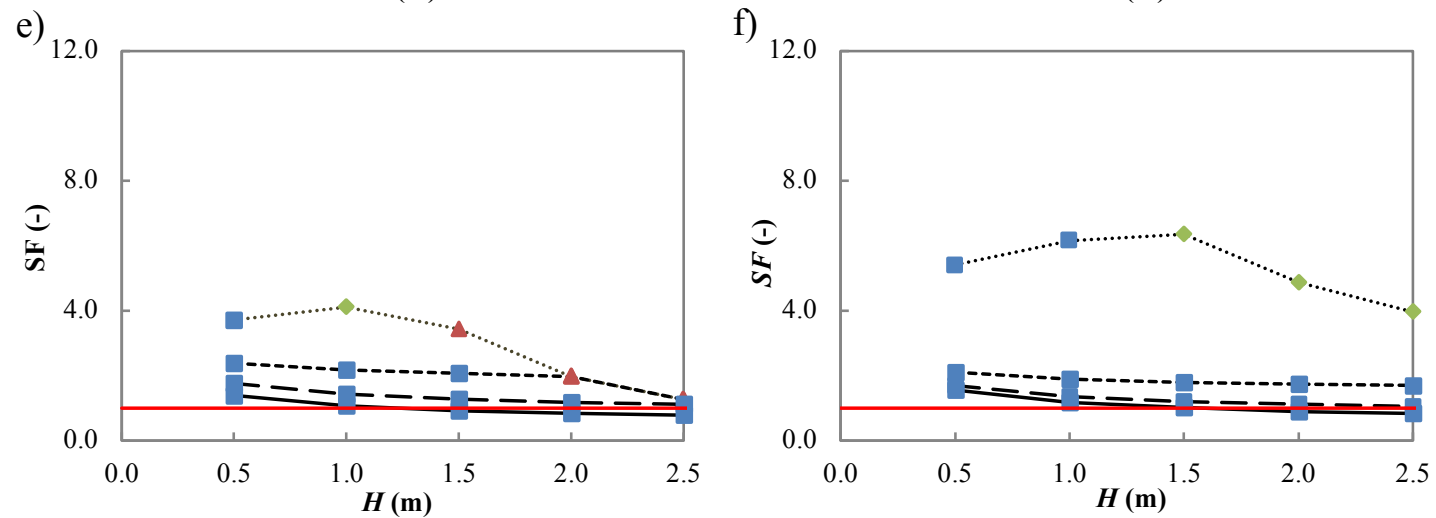

Fig. 5 - Influence of the width of the bag ( $a, b$ and $c)$ and height of the wall (c, $d$ and e) on the SF

Notice that the $S F$ is bigger than 1 for most of the simulations performed. The only exceptions occur for walls with $H$ bigger than $2 \mathrm{~m}$ and is subjected to high $N_{d}$ values. In such cases, the $S F$ against buckling and roll-over becomes smaller than 1. In other words, instability problems become more evident for heights of more than $2 \mathrm{~m}$.

\subsubsection{Interaction axial force and shear force diagram}

In order to gain deeper insight into the structural performance of earthbag walls, an axial force and shear force interaction diagram is developed by means of the equations from Table 1, considering a height of the wall $(H)$ equal to $2.50 \mathrm{~m}$ and the width of the bag $(B)$ equal to 0.45 $\mathrm{m}$. The normal force that generates $S F$ equal to 1 is calculated for each value of shear force 
310 acting at the top of the wall. This calculation is repeated for all failure mechanisms. The 311 resulting diagram is depicted in Fig. 6. An arrow is placed over the curves to indicate whether 312 the safe region regarding each failure mechanism is located above or below the corresponding 313 line. The overall safe region where all verifications are simultaneous fulfilled and the typical 314 load found in practice are also depicted in the figure.

315
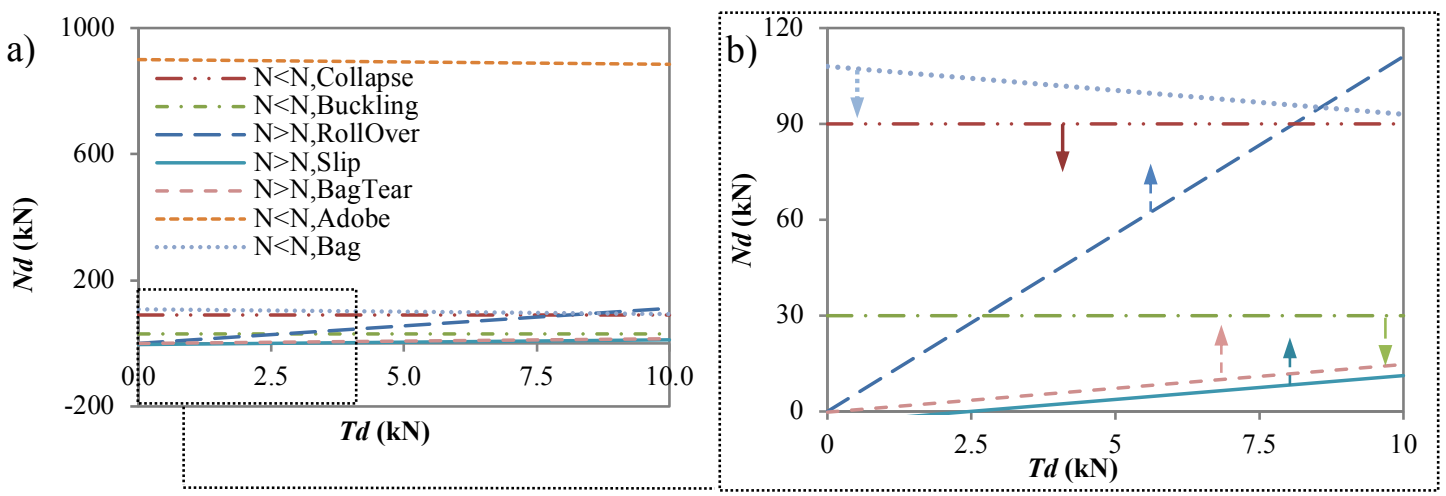

Fig. 6 - Axial and shear forces interaction diagram (a) and zoom of safe region (b)

The load required for producing collapse, bag failure and adobe failure are far above the typical load found in practice. The unsafe region regarding the bag tear and the bag slip covers only a small portion of the typical load area, thus indicating that these modes are not likely to lead to failure. The overall safe region corresponds to the limits established by the expressions regarding buckling and global roll-over. The buckling failure curve is a constant straight line that defines the maximum axial force $30 \mathrm{kN}$, whereas the global roll-over curve exhibits a constant slope that establishes the relationship between the axial and shear forces. Notice that the typical load area is not completely overlapping with the overall safe region, which suggests that the current design might be unsafe. This is mostly due to the high slope of roll-over failure curve. It is important to remark that an isolated wall was considered in this simulation. In many practical situations, the presence of lateral walls increases the stiffness of the structure, thus reducing the slope of the roll-over failure curve.

\section{SUPERADOBE DOMES}

This section focuses on the structural design of superadobe and earthbag domes. The analysis of typical geometries is presented along with the method for the calculation of the stresses in the bags and in the joints. A structural verification of the bearing capacity is also proposed. The results obtained are compared with those derived from the application of alternative methods from the literature. 


\subsection{Geometrical considerations}

343 The superadobe dome presents several particularities when compared with conventional 344 continuous dome structures. The most important of them is related with the material used and 345 the fact that the interaction between biodegradable bags has to be taken into account. Table 4 346 presents the equations that define geometrically typical shapes of superadobe dome.

Table 4 - Equation for the possible arch curvature in height

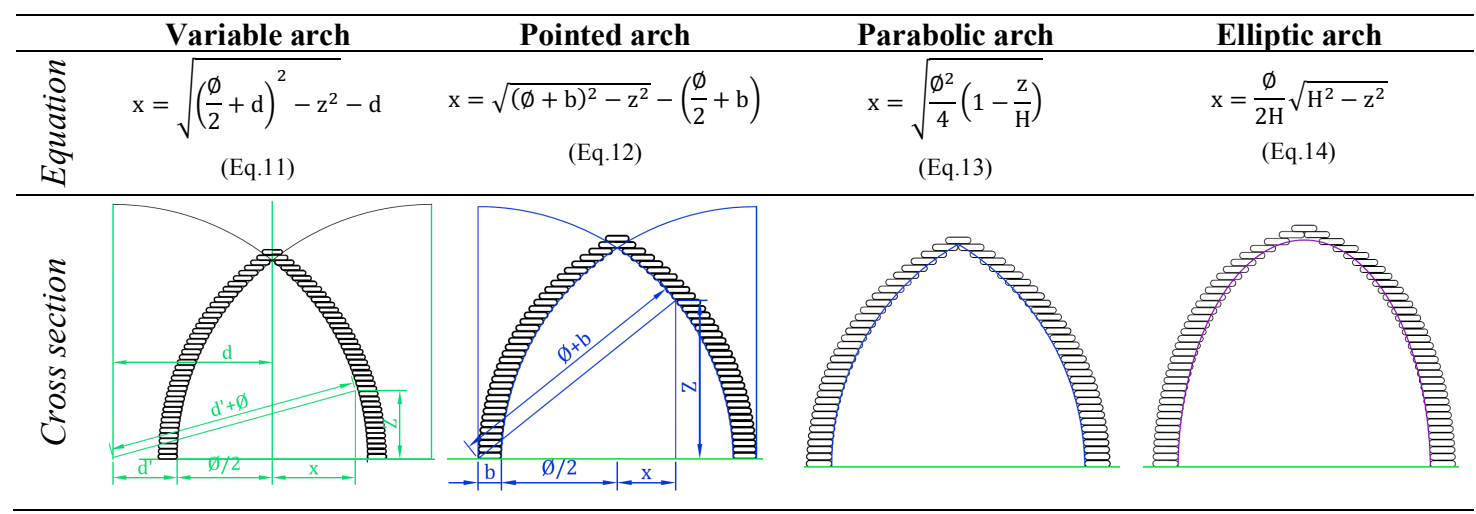

349

350

The most common shape is the "pointed arch" due to its simple construction procedure and its bearing capacity (the geometry provides a significant percentage of rows subjected to compression along the perimeter). While the "pointed arch" and "equilateral arch" only require two ropes to define their geometry, the parabolic and the elliptic ones require a prior set of measurements with regards to the centre of the dome. This might complicate the constructive procedure and should be considered when assessing the optimal shape of the dome.

Among the methods available in the literature to evaluate the stresses of dome-like structure are the membrane theory (MT) and the graphical analysis (GA). The former only applies to pointed arches, whereas the latter applies to any shape. Both of them assume a continuous transmission of stresses along the height, not contemplating the discontinuities introduced by the interfaces between bags. Even though the current design rules (CR) proposed by Khalili (1986) to the design of superadobe domes take that into account such discontinuities, it only applies to pointed arches. The method proposed in the next sections is valid for all superadobe domes, regardless of their shape.

\subsection{Method to estimate the design forces and stresses}

In the design of earthbag and superadobe structures it is essential to consider that the behaviour of the adobe and the bag varies over time. This affects significantly the structure and the way 
the calculations must be made. For early ages, the dome may be assumed as the succession of rows piled one on top of the other, whereas in the long term the dome will behave as a shell stone structure. For this reason, the conventional dome cannot be considered as a reference in the design at early ages. All these aspects were taken into account for the development of the design method. The method is based on the verification that the design forces and stresses do not compromise the stability or lead to mechanical failure. A horizontal force $\left(F_{h}\right)$ needed to centre inside the kern section limits of each row the resultant of the part of the dome located above it is calculated. It is assumed that this force is withstood as shear forces between rows $\left(T_{d}\right)$ or hoop forces along the perimeter of the rows $\left(\sigma_{\theta}\right)$, as shown in Fig. 7. In order to facilitate the comprehension of the method, it was divided in the following seven steps. The equations applied in each step are summarized in Table 5.

1. Calculate the inner (Eq.15), central (Eq.16) and outer radius (Eq.17) of each row defined by the corresponding shape of the dome (Eq.11-14).

2. Classify rows as continuous or discontinuous depending on the presence of open spaces. When the row is continuous define whether bag is capable of bearing hoop stresses or not.

3. Calculate the inner (Eq.18) and outer contact effective limits (Eq.19), the limits corresponding to the kern section (Eq.20-Eq.21) (see Fig.7a) and the contact area between rows (Eq.22).

4. Calculate the weight of each row (Eq.23), the accumulated weight (Eq.24) and the position of the centre of gravity of the accumulated weight (Eq.25-26) (see Fig.7b). Repeat this process for any other type of load acting above the row.

5. Calculate the maximum (Eq.27) and minimum (Eq.28) horizontal forces needed to displace the resultant force towards the kernel section limits (see Fig.7b) of each row.

6. Calculate the axial force (Eq.29), the bending moments (Eq.30-31) and the shear force (Eq.32-33) for each row (see Fig.7c).

7. Calculate the axial stress (Eq.34) through the ratio between the vertical axial force and the effective contact area between consecutive rows. Then, calculate the stress at the most exterior point of the contact (Eq.35) due to the bending moment induced by the weight (see Fig 7d). Finally, calculate the horizontal tensile stress (Eq.36, see Fig.7e). For rows capable of generating hoop forces, calculate the hoop stress in case of compression (Eq.37) or 

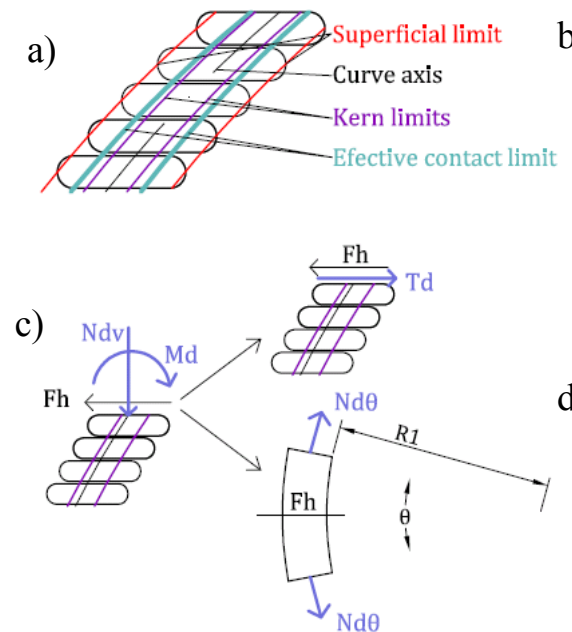

b)

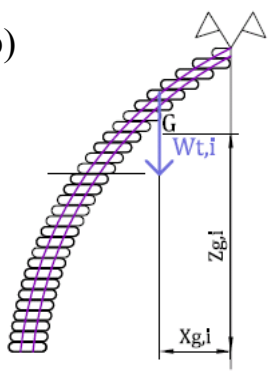

d)

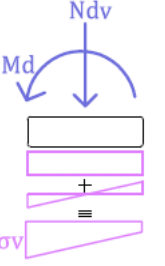

e)
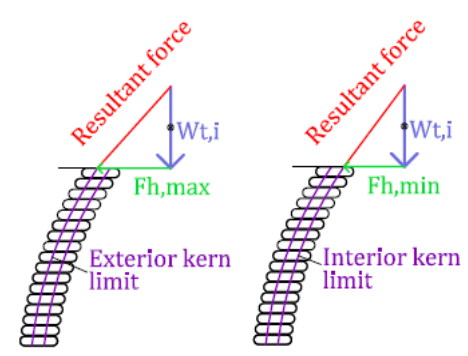

f)

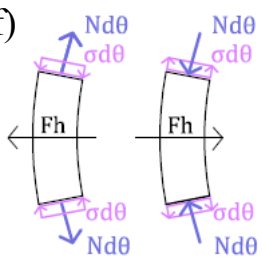

Fig. 7 - Detail of the calculus limits domains (a), the resultant force must be inside of the kern limits (b), force equilibrium (c), distribution of vertical stresses along the adobe section (d), horizontal stresses (e) and hoop forces and stresses due to the radial force (f)

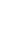

Table 5 - Equations for the estimation of design forces and stresses in domes

\begin{tabular}{|c|c|c|c|c|c|}
\hline Step & Equation & & Step & Equation & \\
\hline \multirow[t]{2}{*}{1} & $R C_{i}=x_{i}+b_{i} / 2$ & (Eq.16) & 5 & $\begin{aligned} F h_{\text {min }, i} & =W t_{i} \frac{R_{k l, i n t, i}-X g_{i}}{Z g_{i}-Z_{i}} \\
F h_{\text {max }, i} & =W t_{i} \frac{R_{k l, e x t, i}-X g_{i}}{Z g_{i}-Z_{i}}\end{aligned}$ & (Eq.28) \\
\hline & $R E_{i}=x_{i}+b_{i}$ & (Eq.17) & \multirow{4}{*}{6} & $N_{d, v, i}=-W t_{i} \gamma_{G 1}$ & (Eq.29) \\
\hline \multirow{4}{*}{3} & \multirow{4}{*}{$\begin{array}{c}R_{e f, e x t, i}=R E_{i-1} \\
R_{k l, i n t, i}=R C_{i}-b_{i} / 6 \\
R_{k l, e x t, i}=R C_{i}+b_{i} / 6 \\
A_{z, e f, i}=2 \pi R C_{i}\left(R_{e f, e x t, i}\right. \\
\left.-R_{e f, i n t, i}\right)\end{array}$} & (Eq.18) & & $M_{d, \min , i}=N_{d, v, i}\left(R_{k l, i n t, i}-R C_{i}\right)$ & (Eq.30) \\
\hline & & $\begin{array}{l}\text { (Eq.19) } \\
\text { (Eq.20) }\end{array}$ & & $\begin{array}{c}M_{d, \max , i}=N_{d, v, i}\left(R_{k l, e x t, i}-R C_{i}\right) \\
T_{d, i}=F h_{\max , i} \gamma_{G 1}\end{array}$ & $\begin{array}{l}\text { (Eq.31) } \\
(\text { Eq.32) }\end{array}$ \\
\hline & & (Eq.21) & & $T_{k, i}=F h_{\min , i} \gamma_{G 2}$ & (Eq.33) \\
\hline & & (Eq.22) & \multirow{5}{*}{7} & $\sigma_{v, i}=-\frac{N_{d, v, i}}{A_{z, e f, i}}$ & (Eq.34) \\
\hline \multirow{4}{*}{4} & $W_{i}=\gamma_{N} 2 \pi R C_{i} b_{i} h$ & (Eq.23) & & $\sigma_{e x t, \max , i}=\sigma_{v, i}-\frac{3 M_{d, \max , i}}{\pi R C_{i} b_{i}{ }^{2}}$ & (Eq.35) \\
\hline & $W t_{i}=\sum_{j=i \max }^{i+1} W_{j}$ & (Eq.24) & & $\sigma_{h, i}=\frac{\sigma_{v, i}}{K_{p}}$ & (Eq.36) \\
\hline & $X g_{i}=\frac{\sum_{j=i \max }^{i+1} W_{j} R C_{j}}{\sum_{j=i \max }^{i+1} W_{j}}$ & (Eq.25) & & $\sigma_{d, \theta, c, i}=\frac{\left(F h_{\min , i}-F h_{\max , i-1}\right) \gamma_{G 1}}{2 \pi b_{i}}$ & (Eq.37) \\
\hline & $Z g_{i}=\frac{\sum_{j=\text { imax }}^{i+1} W_{j} Z_{j}}{\sum_{j=i \max }^{i+1} W_{j}}$ & (Eq.26) & & $\sigma_{d, \theta, t, i}=\frac{\left(F h_{\max , i}-F h_{\min , i-1}\right) \gamma_{G 1}}{2 \pi b_{i}}$ & (Eq.38) \\
\hline
\end{tabular}

409

410 Notice that in the method proposed here, the forces needed to assure that the resultant coincide

411 with the inner and outer kern limits of the cross section are considered. This provides an

412 envelope of forces that mark a limit condition. In safe structures, the real stress will be smaller

413 than the defined with this method. Conversely, if the estimated stresses fall outside these limits,

414 failure or collapse might occur. 


\subsection{Structural verification}

418 The verifications required to confirm the capacity of the superadobe domes to resist the actions 419 applied depend on the behaviour expected from each row. In case openings are presents, the row 420 is considered discontinuous, not being able to bear hoop stresses and falling in the category Ds.

421 In case no opening is present, the row is considered continuous and the designer may decide whether the bags and the adobe are capable of resisting hoop stresses. If the material is capable of bearing both compressive and tensile hoop stresses (the adobe and the bag contribute to the resistant capacity), it falls in the category $C_{A \& B}$. If the material is capable of bearing only compressive hoop stresses (the adobe contributes to the resistant capacity but the bag does not), it falls in the category $C_{A}$.

427 Table 6 shows the expressions for the verification of the failure and resistant mechanisms 428 corresponding to superadobe domes, which are depicted in Fig. 8. The verifications depend on 429 the row classification $\left(D_{s}, C_{A \& B}\right.$ or $\left.C_{A}\right)$. Mandatory and recommended verifications are indicated 430 by the letters $M$ and R, respectively. Notice that the failure mechanisms are analogous the ones described for the superadobe walls in section 3.1.

Table 6 - Structural verification for earthbag or superadobe domes

\begin{tabular}{|c|c|c|c|c|c|c|}
\hline Nature & Mechanism & Verification & & $D_{s}$ & $C_{A}$ & $C_{A \& B}$ \\
\hline \multirow{4}{*}{$\begin{array}{l}\text { Global } \\
\text { stability }\end{array}$} & Roll-over (Fig. 8a) & $W_{t, 1} \gamma_{G 1} / R E_{1} \geq q_{\text {wind }} H^{2} \gamma_{Q 2} / 2$ & (Eq.39) & $\mathrm{M}$ & M & $\mathrm{M}$ \\
\hline & Slipping (Fig. 8b) & $\left(c_{b w} A_{z, \text { ef }, \text { base }}+N_{k, \text { base }} \mu\right) \geq q_{\text {wind }} H \gamma_{Q 2}$ & (Eq.40) & M & M & M \\
\hline & Collapse (Fig. $8 c$ ) & $f_{\text {base }} \geq \sigma_{d, v, 1}$ & (Eq.41) & M & M & M \\
\hline & Buckling (Fig. 8d) & $E_{\text {adobe }} b_{i} / 4 H \geq \sigma_{d, v, \max }$ & (Eq.42) & M & M & M \\
\hline \multirow{2}{*}{$\begin{array}{c}\text { Local } \\
\text { stability }\end{array}$} & Roll-over (Fig. 8e) & $\begin{array}{c}N_{k, v, i}\left(R_{k l, e x t, i}-R E_{i}\right)+W_{i} b_{i} \gamma_{G 1} / 2 \geq T_{d, i} h \\
T_{k, i} h+W_{i} \gamma_{G 1}\left(R C_{i}-R I_{i-1}\right) \geq N_{d, v, i}\left(R_{k l, i n t, i}-R I_{i-1}\right)\end{array}$ & $\begin{array}{l}(\text { Eq.43) } \\
(\text { Eq.44) }\end{array}$ & $\begin{array}{l}M \\
M\end{array}$ & $\begin{array}{l}M \\
M\end{array}$ & $\begin{array}{l}\mathrm{M} \\
\mathrm{M}\end{array}$ \\
\hline & Slipping (Fig. 8f) & $c_{b w} A_{z, e f, i} / \gamma_{\text {wire }}+N_{k, v, i} \mu \geq T_{d, i} *$ & (Eq.45) & M & & \\
\hline \multirow{3}{*}{$\begin{array}{l}\text { Local } \\
\text { strength } \\
\text { of the } \\
\text { material }\end{array}$} & Bag tear (Fig. $8 g$ ) & $T_{\text {tear }} \geq T_{d, i}-N_{d, i} \mu$ & (Eq.46) & & & $\mathrm{R}$ \\
\hline & $\begin{array}{l}\text { Adobe failure } \\
\text { (Fig. } 8 h \text { ) }\end{array}$ & $\begin{array}{c}-f_{\text {adobe }} \geq \sigma_{d, e x t, \max , i} \\
-f_{\text {adobe }} \geq \sigma_{d, \theta, \mathrm{c}, i} \\
f_{\text {adobe } \mathrm{t}} \geq \sigma_{d, \theta, \mathrm{t}, i} * *\end{array}$ & $\begin{array}{l}(\text { Eq.47) } \\
(\text { Eq.48) } \\
(\text { Eq.49) }\end{array}$ & M & $\begin{array}{c}\mathrm{M} \\
\mathrm{M}^{*} \\
\mathrm{M}^{*}\end{array}$ & $\begin{array}{c}\mathrm{M} \\
\mathrm{M}^{*}\end{array}$ \\
\hline & $\begin{array}{l}\text { Bag failure } \\
\text { (Fig. 8i) }\end{array}$ & $\begin{array}{c}2 K_{p} T_{b a g} /\left(\mathrm{h} \gamma_{b a g}\right) \geq \sigma_{d, e x t, \text { max }, i} \\
T_{b a g}\left(b_{i}+h\right) /\left(b_{i} h \gamma_{b a g}\right) \geq \sigma_{d, \theta, \mathrm{t}, i}\end{array}$ & $\begin{array}{l}(\text { Eq.50) } \\
(\text { Eq.51) }\end{array}$ & & & $\begin{array}{c}\mathrm{M} \\
\mathrm{M}^{* *}, *\end{array}$ \\
\hline
\end{tabular}



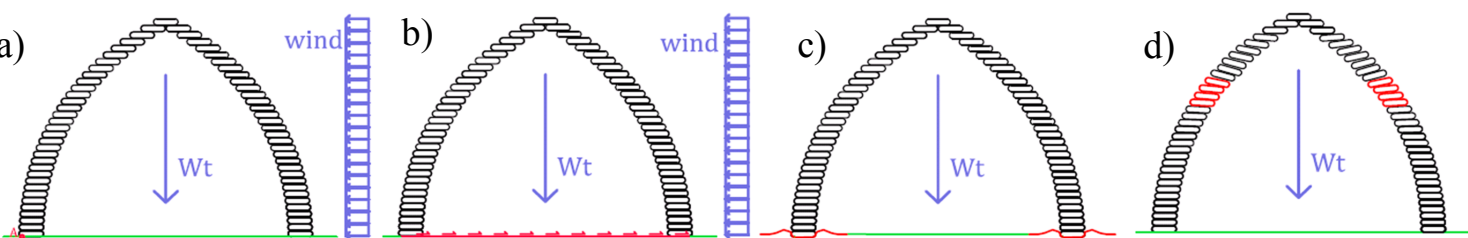

e)

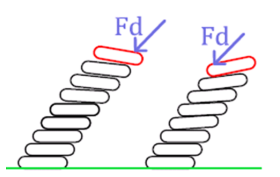

f)

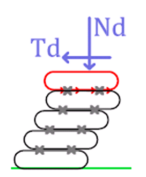

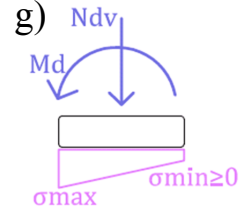

h)
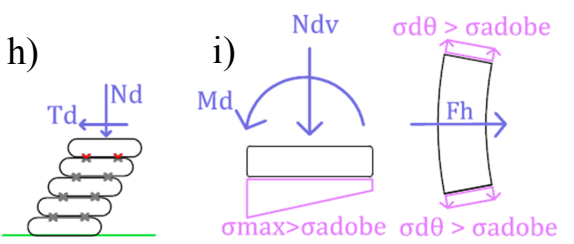

j)

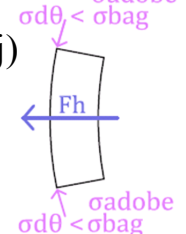

Fig. 8 - Failure schemes according to Table 5 (Eq. 39-51): Global roll-over (a), global slipping (b), collapse (c), buckling (d), local roll-over (e), local slipping $(f)$, vertical compression (g), tear of the bag

(h), adobe failures (i) and bag or adobe failure in hoop direction (j)

441

\subsection{Comparison with finite element numerical simulation}

443

\subsubsection{Description of the FEM}

445

In order to confirm that the method proposed shows reasonable structural response, numerical validations with finite element simulations were performed. The finite element program "TNO Diana 9.3" was used for this purpose. An axisymmetric model was selected due to the geometry of the dome. Bags were represented by triangular elements with an integration point at each side and maximum dimension of $10 \mathrm{~mm}$. Fig. 9a shows the mesh used in this study.

a)

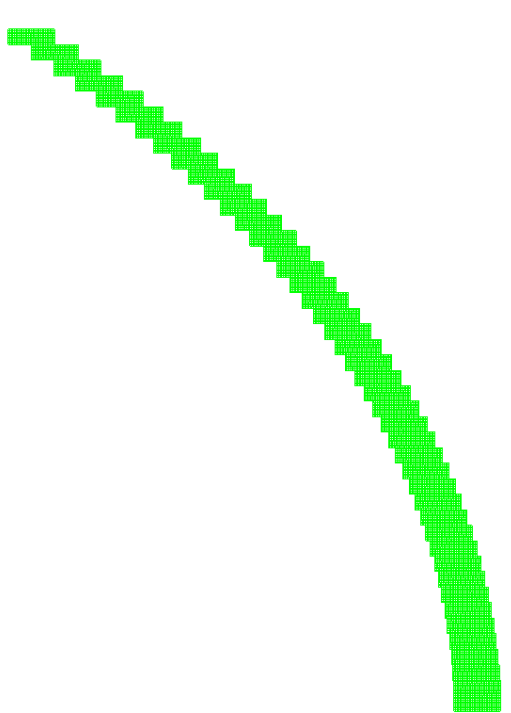

b)

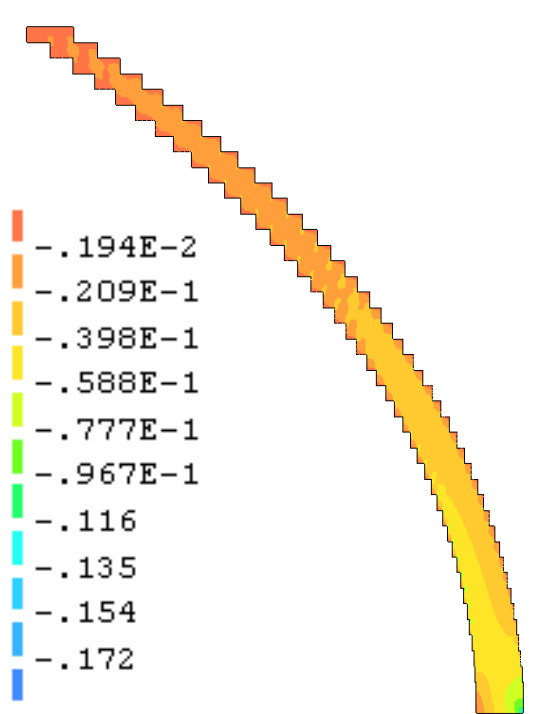


455 The constitutive model used for the earthbag shows an elasto-plastic behaviour in compression.

456 It follows the Hook's law with strains linearly proportional to stress until the yield stress of the

457 adobe is reached. Once this occurs, the strain increases without any increment of the stress. A

458 brittle failure in tension with cut-off strength of $0 \mathrm{MPa}$ is assumed to simulate the behaviour of

459 the adobe at early ages. Structural interface elements were placed in the joint between earthbags

460 to simulate their interaction. A Coulomb Friction model was used to capture the possible sliding

461 in the interface. This model requires the input of a cohesion value and a friction coefficient.

462 Table 7 shows the elastic modulus $\left(E_{\text {adobe }}\right)$, Poisson ratio $(v)$ and the density $(D)$ of the adobe

463 used in all analyses. The same table also presents the cohesion $\left(C_{b w}\right)$ and the friction coefficient

$464\left(\mu_{b a g s}\right)$ of the interfaces.

Table 7 - Geometry and material properties for the comparison with the FEM

\begin{tabular}{ccccccccc}
\hline $\boldsymbol{B}(\mathbf{m})$ & $\boldsymbol{b}(\mathbf{m})$ & $\boldsymbol{h}(\mathbf{m})$ & $\boldsymbol{D}\left(\mathbf{k N} / \mathbf{m}^{3}\right)$ & $\boldsymbol{K}_{p}(-)$ & $\boldsymbol{E}_{\text {adobe }}\left(\mathbf{k N} / \mathbf{m}^{2}\right)$ & $\boldsymbol{v}(-)$ & $\boldsymbol{C}_{b w}\left(\mathbf{k N} / \mathbf{m}^{2}\right)$ & $\boldsymbol{\mu}_{\text {bags }}(-)$ \\
\hline 0.5 & 0.355 & 0.145 & 19.00 & 2.40 & 10000.00 & 0.30 & 5.50 & 0.67 \\
\hline
\end{tabular}

The displacement of the lowest row of earthbags was fully restrained. The load consisted of the self-weight of the elements applied in the direction of the height of the dome. The tenth part of the self-weight was applied in 10 successive steps to evaluate the arising of material nonlinearities. The solution to each load step was obtained through an iterative procedure based on the Newton-Rapson approach. Fig. 9b shows a typical stress distribution obtained after the load is fully applied.

a) 3.2

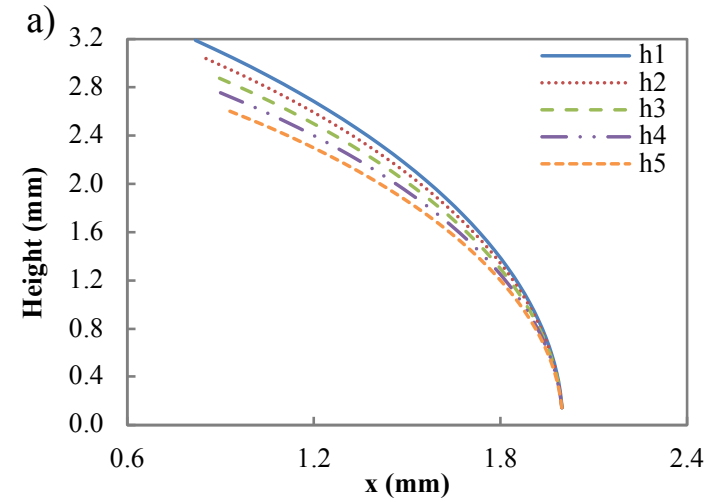

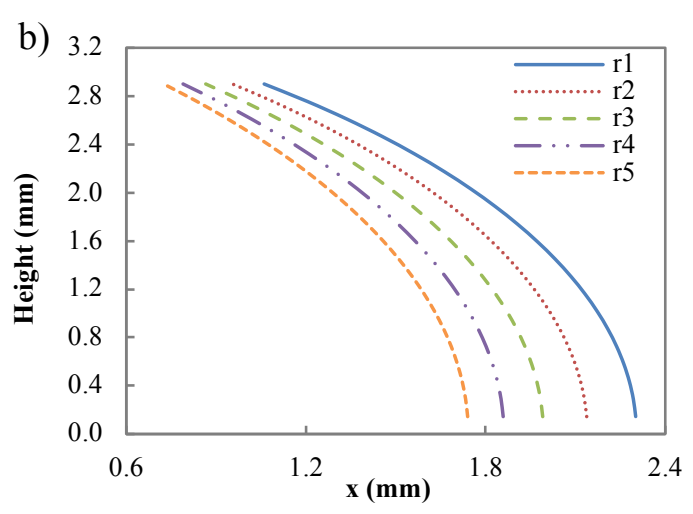

Fig. 10 - Arches simulated: constant the radius and variable height (a), constant height and variable the

radius (b)

480 A parametric study was conducted by varying the height and the radius of an ogival arch as 481 shown in Fig.10a and Fig.10b. In the analysis of the influence of the height, values ranging from $4822.6 \mathrm{~m}$ to $3.2 \mathrm{~m}$ were used for an inner radius of $2.0 \mathrm{~m}$. For the analysis of the influence of the 
inner radius, values ranging between $1.7 \mathrm{~m}$ and 2.3 were used, considering a height of $2.9 \mathrm{~m}$. Other geometric parameters assumed in the simulations are summarized in Table 6. In total 10 models were analysed. No partial safety factor was applied to the loads or to the material properties. After the analysis, the resultant force was calculated at each height through a weighted sum of the forces acting at all nodes at this height.

\subsubsection{Results of the FEM}

490

Fig. 11 shows the results obtained with the finite elements models (FEM) and in the design method proposed here (MP). Fig. 11a, $11 \mathrm{~b}$ and $11 \mathrm{c}$ represent the variation of vertical $\left(\sigma_{v}\right)$, shear $(\tau)$ and hoop $\left(\sigma_{\theta}\right)$ stresses for models with different height (h1 to h5). Fig. 11d, 11e and 11f show 495

496

497 analogous results for models with different radius (r1 to r5).

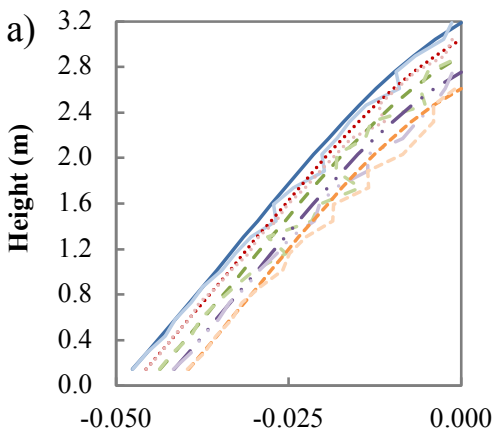

b)

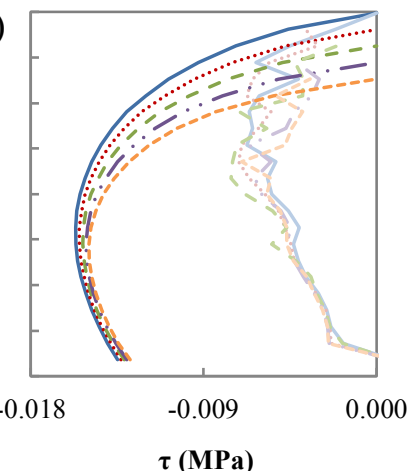

$\sigma_{\mathrm{v}}$ (MPa) c)

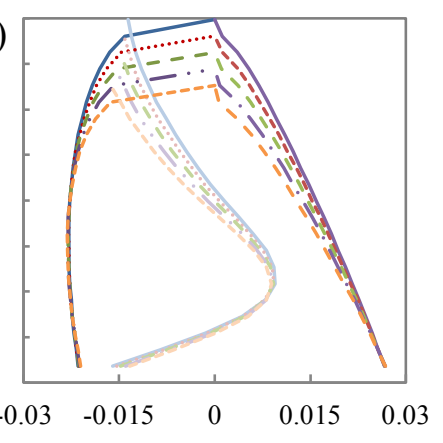

$\sigma_{\theta}(\mathrm{MPa})$
498

499

500

501

502
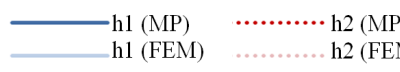

h2 (MEM) e)

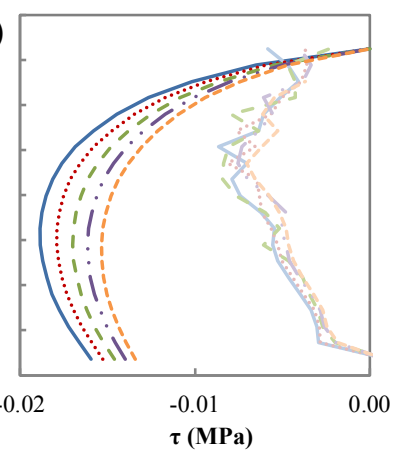

f)

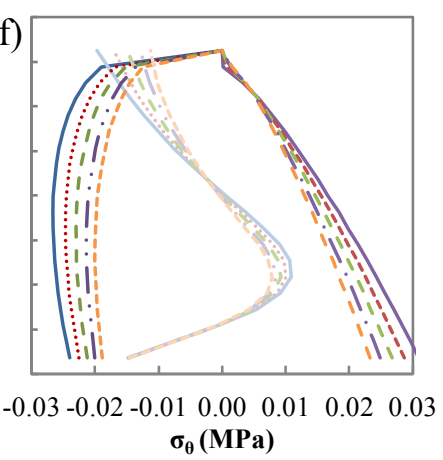

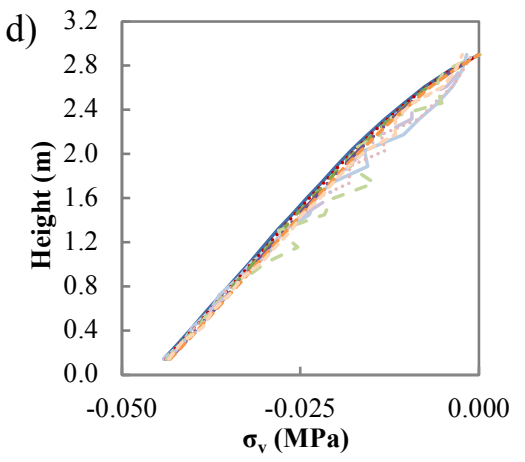

2 (MP) $\quad---r 3$ (MP) $\quad-\cdots-r 4(\mathrm{MP})$

$\mathrm{r} 2$ (FEM) - - - r3 (FEM) - . - r 4 (FEM)

Fig. 11 - Comparison of vertical $\left(\sigma_{v}\right)$, shear $(\tau)$ and hoop stress $\left(\sigma_{\theta}\right)$ computed by MP and FEM for different curvatures: varying the height $(a, b, c)$ and varying the radius curves $(d, e, f)$

The vertical stresses increase almost linearly with the height as a consequence of the increase of the number of rows supported. The vertical stresses computed with the model proposed here and the finite element simulation are almost the same for all curves. Small differences may be 
attributed to the procedure of calculation of the stresses in the latter since an averaging 507 procedure has to be applied.

508 The shear stress obtained at the top of the dome is approximately $0 \mathrm{MPa}$ since the key element 509 is at a stable position. These stresses increase rapidly as the height reduces. Tangential forces 510 are needed to guarantee compatibility and to divert the resultant force of the upper rows due to 511 the change in the radial position of the cross section centre of gravity at each height. For the 512 same reason, at lower height, the smaller change in radial position of successive rows implies 513 smaller values of shear stress. Even though the shape of the curves is similar, the stresses 514 calculated with the methodology proposed here is considerably higher than the calculated 515 through the finite element analysis. This result was expected since the proposed method shows a 516 limit situation that could lead to collapse or local failure.

517 The hoop stresses computed in the finite element simulation changes direction along the height 518 of the dome. This is a consequence of the compatibility of displacements experienced by the 519 dome. The simplified method proposed does not take into account these deformations, which 520 otherwise would compromise the simplicity of the calculations. Consequently, it is not able to capture the change in the direction of the hoop stresses. Despite that, the fact that the calculation is performed for the outer and inner limits of the kern of the cross section for compression and tensile forces provides maximum and minimum values. Notice that all curves obtained with the finite element simulations remain within the limits defined by the curves of the simplified method. This confirms that the simplified method will always remain on the safe side.

\subsection{Comparison with other simplified approaches from the literature}

To understand the repercussion of the new design method proposed, a comparison with other simplified approaches from the literature is made. In total, three approaches were selected: the graphical analysis (GA) (Wolfe 1921), the membrane theory (MT) (Billington 1982) and the current design rules (CR) (Khalili 1986). All analyses were conducted considering the geometric and material properties from Table 7 and a pointed arch shape. Fig.12a compares the minimum bag width required to build domes with diameter $(\phi)$ ranging from $3.0 \mathrm{~m}$ to $6.0 \mathrm{~m}$.

535 Fig. 12a indicates that the current design rules (CR) and the model proposed here (MP) give 536 similar design for diameters bigger than $4.0 \mathrm{~m}$. For diameters of less than $4.0 \mathrm{~m}$, MP yields smaller thickness than the CR. This indicates that the CR might lead to an overestimated design, which may be attributed to some simplifications assumed in this method. Notice that for a $5.0 \mathrm{~m}$ dome, the optimized bag size is $0.45,0.65,0.65$ and 0.85 for MT, CR, MP and GA,

540 respectively. This indicates that GA overestimates the minimum bag width by $70 \%$ in 541 comparison with CR and MP. Such outcome may be attributed to the fact that the resultant from 
542 the GA tends to fall outside the kern of the earthbags. Consequently, it is necessary to increase 543 the width to assure that forces falls within these limits.

544

545

546

547

548

549

550

551

552

553

554

555

556

557

558

559

560

561

562

563

564

565

566

567

568

569

570

571 a)

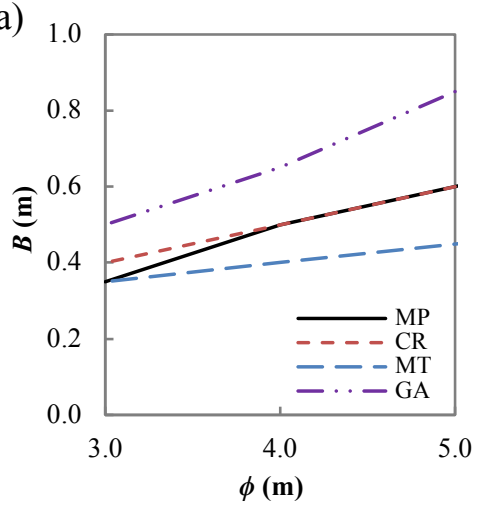

b)

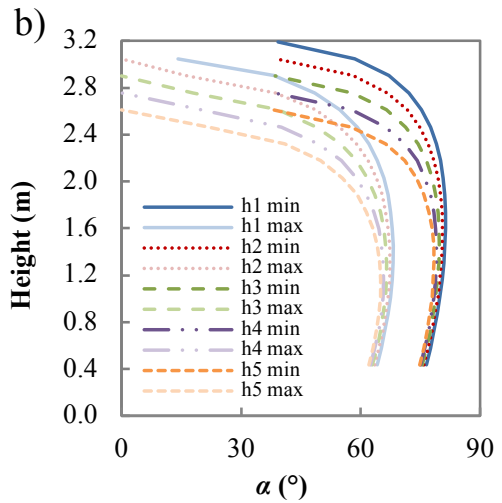

c)

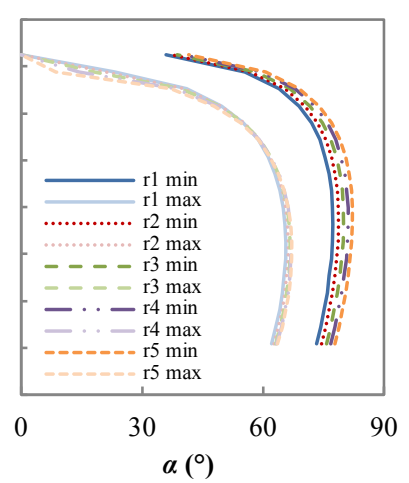

Fig. 12 - Comparison of dome design following MP, CR, MT and GA; range of stabilizing angles of CM to obtain the same moment than MP ( $b$ and $c$ )

On the contrary, the MT underestimates the results from CR and MP by $10 \%$. The reason for that is the limited capacity of the MT to capture the failure mode observed in the domes, which is due to local roll-over. This type of failure is only observed in the domes analyzed with the MT in case very small width is used. In other words, it only occurs for domes with smaller width.

A new method for the analysis of superadobe domes is the modified corbelling theory (CM) (Rovero and Tonietti 2012, Rovero and Tonietti 2014). The latter introduces a stabilizing parameter in order to add the contribution of the hoop curvature on the over-roll equilibrium. This parameter is called $\alpha$ and is the influence angle that reduces the destabilizing moment and increases the stabilizing one. The main inconvenient of the $\mathrm{CM}$ is that this parameter depends on the characteristics of each dome, requiring experimental studies. It is important to remark that a direct comparison with the corbelling theory $(\mathrm{CM})$ is not possible since it does not provide the design width of the dome. Despite that, a comparison is made in terms of the angle $\alpha$ that has to be used in the $\mathrm{CM}$ to obtain the maximum and minimum bending moment equilibrium found in the model proposed here. The angle obtained is compared with the range typically found by Rovero and Tonietti (2014).

Fig. $12 \mathrm{~b}$ and $12 \mathrm{c}$ shows the results obtained for the arch shapes of Fig. 10. Although lower values are found at the upper part of the dome, the results indicates that the range of angles must be between $60^{\circ}$ and $85^{\circ}$ on bottom rows. This range of $\alpha$ is in agreement with that estimated in the studies with the CM based on experimental result from other authors, who found values of $72.5^{\circ}$ and $75.7^{\circ}$ for real domes (Rovero and Tonietti 2014). 


\subsection{Parametric study}

575 Table 8 shows the range of variables and the fixed values of properties used in the parametric study of the domes using the method proposed. Again, the selection of parameters and their ranges intend to cover typical values found in practice, being based in studies from the literature and on the experience by the authors. The arch is simulated in this case by changing the parameter $d$ ' that governs the curvature according with Eq. 12. Variables are analysed one by one, considering all other parameters with fixed values. In this sense, $B, C_{b w}, \mu_{b a g s}$ and $d^{\prime}$ are assumed equal to $0.5 \mathrm{~m}, 6.0 \mathrm{kN} / \mathrm{m}^{2}, 0.6$ and $1.0 \mathrm{~m}$, respectively. The estimation of the safety factor was performed as described in section 2.2 considering domes with discontinuous behaviour $\left(D_{s}\right)$ and domes with a continuous behaviour that are capable of resisting tensile and compressive hoop stresses $\left(C_{A \& B}\right)$. The diameters simulated ranged from 3.0 to $6.0 \mathrm{~m}$.

Table 8 - Geometric and material properties for the parametric study of the domes

\begin{tabular}{|c|c|c|c|c|c|c|c|c|c|c|c|c|}
\hline $\begin{array}{c}B \\
(m)\end{array}$ & $\begin{array}{c}d^{\prime} \\
\text { (m) }\end{array}$ & $\begin{array}{c}\phi \\
(m)\end{array}$ & $\begin{array}{c}D \\
\left(k N / m^{3}\right)\end{array}$ & $\begin{array}{l}\boldsymbol{K}_{p} \\
(-)\end{array}$ & $\begin{array}{c}E_{\text {adobe }} \\
\left(\mathrm{kN} / \mathrm{m}^{2}\right)\end{array}$ & $\begin{array}{c}f_{\text {adobe }} \\
\left(\mathrm{kN} / \mathrm{m}^{2}\right)\end{array}$ & $\begin{array}{c}f_{\text {adobe } t} \\
\left(\mathrm{kN} / \mathrm{m}^{2}\right)\end{array}$ & $\begin{array}{c}f_{\text {ground }} \\
\left(\mathbf{k N} / \mathbf{m}^{2}\right)\end{array}$ & $\begin{array}{c}T_{b a g} \\
(\mathrm{kN} / \mathrm{m})\end{array}$ & $\begin{array}{l}T_{\text {tear }} \\
(\boldsymbol{k N})\end{array}$ & $\begin{array}{c}C_{b w} \\
\left(\mathrm{kN} / \mathbf{m}^{2}\right)\end{array}$ & $\begin{array}{c}\mu_{b a g s} \\
(-)\end{array}$ \\
\hline $\begin{array}{c}0.3 \text { to } \\
0.6\end{array}$ & $\begin{array}{c}0 \\
\text { to } \\
1.5\end{array}$ & $\begin{array}{c}3 \\
\text { to } \\
6\end{array}$ & 19 & 2.40 & 10000 & 2000 & 20 & 200 & 10 & 0.14 & $\begin{array}{c}0 \\
\text { to } \\
6\end{array}$ & $\begin{array}{c}0 \\
\text { to } \\
0.6\end{array}$ \\
\hline
\end{tabular}

Fig. 13a shows the influence of the width of the bag on the $S F$. The increase of width leads to a consequent increase of the $S F$ in the domes $C_{A \& B}$. This is reasonable given that the failure in this case is governed by the roll-over to the outside in the rows close to the bottom of the dome. The increase of the width leads to bigger contact areas, which contributes to the stability against this type of failure and increases the $S F$. On the contrary, the predominant failure mechanism observed in the discontinuous domes $\left(D_{s}\right)$ is due to slipping between bags. In this case, the higher self-weigh load induced by the bigger width leads to bigger tangential loads that contribute to the slipping of the bags located at the zones close to the top of the dome, which are subjected to reduced normal forces. Consequently, smaller $S F$ are obtained as the width

598 The influence of the parameters $C_{b w}$ and $\mu$ that determine the behaviour of the interface between

599 bags are depicted in Fig.13b and 13c. Notice that both parameters have no influence in safety 600 factor of the continuous domes since the main failure mechanism is due to roll-over and, 601 therefore, do not depend on the interface properties. On the contrary, the discontinuous domes 602 show a significant increase of the $S F$ as $C_{b w}$ and $\mu$ increase. This is reasonable since the failure 603 in this case is governing by the slipping of the bags, thus depending on the properties of the 604 interface. 
Fig. 13d shows the influence of the curvature parameter $d$ ' on the $S F$. In general, the selection of smother curvatures (bigger $d$ ') leads to an increase on the $S F$. This becomes more evident as the diameter of the domes increases. This outcome is reasonable since smaller tangential forces are generated with smother curvatures, reducing the risk of global and local instabilities.

609
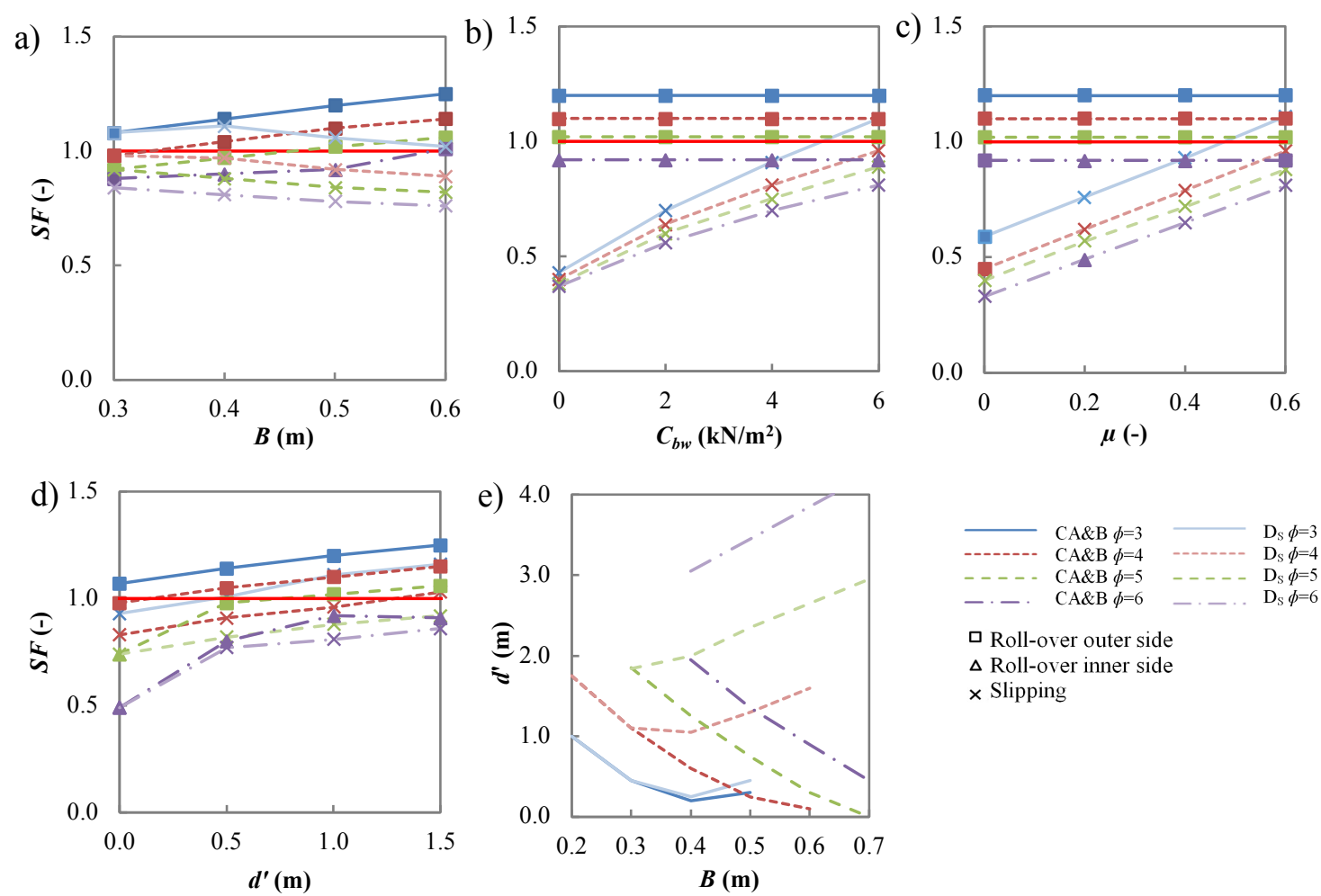

Fig. 13 - Influence of the width of the bag (a), the cohesion of the interface (b), the friction coefficient

between bags (c) and the curvature parameter (d) on the safety factor and the optimal design of the

curvature parameter (e)

624 Based on these results, an optimization analysis was performed to identify the minimum curvature parameter $\left(d^{\prime}\right)$ that yields a $S F$ equal to 1 for each combination of the width of the bag and the diameter of the dome, thus minimizing the consumption of material and the construction time. The curves obtained in this study are presented in the interaction diagram of Fig. 13e. The results reveal that an increase in the diameter requires an increase in the parameter $d^{\prime}$ '. In fact, smoother curvatures are needed to cover bigger spans without generating critical tangential stresses or the roll-over failure. It is also evident that the parameter $d$ ' tends to decrease with the width of the bags for all diameters. Nevertheless, discontinuous domes or domes with smaller diameter show a width above which the $d$ ' required increases. In other words, an optimum width exists in these cases and could be determined through the use of the alternative method proposed here. 
638 The earthbag technique is an alternative to promote social housing and emergency shelters due

639 its simplicity, fast construction and low cost. In spite of all this advantages, a lack of design 640 methods that take into account the specificities of this type of structures might compromise its efficient and safe use. For that, several resistant mechanisms were identified and an alternative method for the design of walls and domes was proposed. This method takes into account the material properties and the capability of bearing tension on continuous hoops. The following conclusions may be derived from this study.

- The most probable failure mechanism in superadobe walls are the global roll-over and buckling. The increase of lateral stiffness is recommended to reduce the risk of these failure modes. The simulations performed suggest that the increase of stiffness will extend the resistance of the wall and change the most likely failure mode, which will be governed by failure or tear of the bag.

- The parametric study indicates that the wall width is the variable with greatest influence on structural safety, affecting in all the failure mechanisms considered. Conversely, the barbed wire contribution in straight walls is irrelevant because the slipping mechanism hardly ever will occur. In such situations, this material can be eliminated of the straight walls.

- The critical failure mode for the domes is the roll-over towards the outside that occurs close to the bottom and slipping close to the top. The width of the bags and the curvature of the dome are the most important parameters governing the structural response. It was found that for domes with big diameters and discontinuous domes, the increase of the width might lead to a reduction of the safety factor. In other words, an optimum width may be obtained.

- The application of the method proposed here allows the definition of optimization diagrams that relate the width of the bag, the curvature and diameter of the dome, as shown in Fig.13. These diagrams might serve as a fast reference to obtain the combination of parameters that minimizes the consumption of materials and the construction process.

- The method proposed has been verified with finite element simulations regarding normal vertical, shear and hoop stresses, for different dome sizes curvatures. The results obtained with the method proposed here is on the safe side for all cases analysed.

- Regarding to methodologies for the calculation of dome stresses, the membrane theory cannot capture the roll-over failure, which usually is the critical one; therefore the wall 
size is underestimated. The use of graphical analysis yields an overestimated design. For that reason, the use of the membrane theory and of the graphical analysis for the design of domes should be avoided in favour of the method proposed here or of the one proposed by Khalili (1986).

\section{ACKNOWLEDGEMENTS}

The authors would like to acknowledge Iliona Khalili and Domoterra for their kind support and for providing information regarding constructed earthbag and superadobe structures.

\section{REFERENCES}

ABNT. NBR 10833. Fabricação de tijolo maciço e bloco vazado de solo cimento com utilização de prensa hidráulica. Associação Brasileira de Normas Técnicas, Rio de Janeiro, 1998 (in Portuguese).

AENOR. UNE 41410:2008. Bloques de tierra comprimida para muros y tabiques. Definiciones, especificaciones y métodos de ensayo. Asociación Española de Normalización y Certificación, Madrid, 2008 (in Spanish).

ASTM E2392 M-10. Standard Guide for Design of Earthen Wall Building Systems. American Society for Testing and Materials, West Conshohocken, PA; 2010.

Billington, D. P. Thin shell concrete strucutres. McGraw-Hill. New York; 1982.

Cid, J., Mazarrón, F.R. and Cañas, I. Las normativas de construcción en tierra en el mundo, Informes de la Construcción, 64(523):159-169, 2011 (in Spanish).

Croft C. Structural resistance of earthbag housing subject to horizontal loading. Master Thesis, University of Bath, Bath, 2011.

Daigle B. Earthbag Housing: Structural Behaviour and Applicability in Developing Countries. Master Thesis. Queen's University, Kingston, 2008.

Geiger O. Earthbag Building guide: vertical walls step by step. Excellence in natural building; 2011.

Hunter, K. and Kiffmeyer, D. Earthbag building: the tools, tricks and techniques. New Society Publishers, Gabriola Island, 2004.

Khalili, N. Ceramic houses and earth architecture: how to build your own. San Francisco: Harper \& Row, 1986.

Khalili, N. and Vittore, P. Earth architecture and ceramics: the sandbag/superadobe/superblock construction system. International Conference of Building Officials, Building standards, 1998. 
706 Lohani, T., Matsushima, K., Aqil, U., Mohri, Y. and Tatsuoka, F. Evaluating the strength

707 and deformation characteristics of a soil bag pile from full-scale laboratory test,

708 Geosynthetics International, 13(6):246-264, 2006.

709 Minke, G. Construction manual for earthquake resistant houses built of earth. Gate-Basin and 710 GTZ GmbH, Eschborn, 2001.

711 Pelly, R. Plastic limit analysis of earthbag structures. Master Thesis, University of Bath; 2010.

712 Robin, V., Javadi, A.A., Cuisinier O. and Masrouri F. An effective constitutive model for limed 713 treated soils, Computers and Geotechnics, 66:189-202, 2015.

714 Rovero, L. and Tonietti, U. Structural behaviour of earthen corbelled domes in the Alleppo's 715 region, Material and Structures, 45(1):171-184, 2012.

716 Rovero, L. and Tonietti, U. A modified corbelling theory for domes with horizontal layers,

717 Construction and Building Materials, 50:50-61, 2014.

718 Tantono, S. The mechanical behaviour of a soilbag under vertical compression. Doctoral Thesis, 719 Graz University of Technology, 2007.

720 Teslik, J.Z. and Vodicková, N.M. Air-tightness and acoustic properties of SuperAdobe system.

721 Advanced materials research. 899:365-368, 2014.

722 Vadgama N. A material and structural analysis of earthbag housing. Master Thesis, University 723 of Bath, Bath, 2010.

724 Wojciechowska P. Building with earth: a guide flexible form earthbag construction. Chelsea 725 Green; 2001.

726 Wolfe, W.S. Graphical analysis: A text book on graphic statics. New York: McGraw-Hill Book 727 Co, New York, 1921, p250-253.

728 Zhao, Z., Lu, Q., Jiang, X. An Energy Efficient Building System Using Natural Resources 729 Superadobe System Research, Procedia Engineering, 121:1179-1185, 2015.

731 Symbols

$\begin{array}{lll}732 & A_{d} & \text { Design value of the effects of actions } \\ 733 & A_{v, e f} & \text { Vertical effective contact area of a row } \\ 734 & B & \text { Bag width } \\ 735 & b & \text { Row width } \\ 736 & C & \text { Corbelled dome method } \\ 737 & C_{A} & \text { Continuous row } \\ 738 & C_{A \& B} & \text { Continuous row with bag bears hoop tractions } \\ 739 & C_{b w} & \text { Cohesion of the contact between joints with barbwire } \\ 740 & C M & \text { Corbelled dome method modified } \\ 741 & C R & \text { Current dome rules design } \\ 742 & D & \text { Adobe density } \\ 743 & D s & \text { Discontinuous row } \\ 744 & E_{a d o b e} & \text { Adobe elastic modulus }\end{array}$




\begin{tabular}{|c|c|c|}
\hline 745 & $f_{\text {adobe }}$ & Yield stress of the adobe \\
\hline 746 & $f_{\text {ground }}$ & Ground collapse load \\
\hline 747 & $F h$ & Radial force \\
\hline 748 & $F_{d}$ & Design value of a force \\
\hline 749 & FEM & Finite element method \\
\hline 750 & $G A$ & Graphical analysis \\
\hline 751 & $H$ & Structure total height \\
\hline 752 & $h$ & Row height \\
\hline 753 & $i$ & Row object to study \\
\hline 754 & $\operatorname{imax}$ & Top row \\
\hline 755 & $I_{x}$ & Moment of inertia \\
\hline 756 & $K_{p}$ & Coefficient of lateral earth pressure \\
\hline 757 & $L$ & Wall length \\
\hline 758 & $M_{\mathrm{d}}$ & Design bending moment \\
\hline 759 & $M P$ & Method proposed in this study \\
\hline 760 & $M T$ & Membrane theory \\
\hline 761 & $N_{\mathrm{d}}$ & Design value of a normal force \\
\hline 762 & $N_{\mathrm{k}}$ & Design value for a favourable normal force \\
\hline 763 & $q_{\text {wind }}$ & Wind load \\
\hline 764 & $R I$ & Inner radius \\
\hline 765 & $R C$ & Middle row radius \\
\hline 766 & $R E$ & Outer radius \\
\hline 767 & $R E_{l}$ & Outer radius of the first row \\
\hline 768 & $R_{e f, \text { int }}$ & Interior radius of the effective contact limit \\
\hline 769 & $R_{e f, e x t}$ & Exterior radius of the effective contact limit \\
\hline 770 & $R_{k l, \text { int }}$ & Interior radius of the kern section limit \\
\hline 771 & $R_{k l, e x t}$ & Exterior radius of the kern section limit \\
\hline 772 & $S_{d}$ & Design value of the strength effects \\
\hline 773 & $T_{\text {bag }}$ & Tensile strength of the bag \\
\hline 774 & $T_{d}$ & Design value of a shear force \\
\hline 775 & $T_{\text {tear }}$ & Tear strength of the bag per unit of length \\
\hline 776 & $W_{\text {dome }}$ & Total dome weight \\
\hline 777 & $W_{i}$ & Weight of the row section $i$ \\
\hline 778 & $W t_{i}$ & Total weight which received the row section $i$ \\
\hline 779 & $x$ & Interior radial dome distance \\
\hline 780 & $X g$ & Center of gravity in radial coordinates \\
\hline 781 & $Y_{\max }$ & Maximum distance of neutral axis \\
\hline 782 & $Z g$ & Center of gravity in height coordinates \\
\hline 783 & $z_{i}$ & Height position \\
\hline 784 & $\alpha$ & Stabilizing parameter for the corbelled modified theory \\
\hline 785 & $\varnothing$ & Interior dome diameter \\
\hline 786 & $\gamma_{\text {adobe }}$ & Adobe strength reductor coefficient \\
\hline 787 & $\gamma_{\text {bag }}$ & Bag strength reductor coefficient \\
\hline 788 & $\gamma_{\mathrm{G} 1}$ & Partial safety coefficient for a favorable permanent load \\
\hline 789 & $\gamma_{\mathrm{G} 2}$ & Partial safety coefficient for a unfavorable permanent load \\
\hline
\end{tabular}




$\begin{array}{lll}790 & \gamma_{\mathrm{N}} & \text { Specific weight } \\ 791 & \gamma_{\mathrm{Q} 2} & \text { Partial safety coefficient for a unfavorable variable load } \\ 792 & \gamma_{\text {wire }} & \text { Barbed wire strength reductor coefficient } \\ 793 & \sigma_{d, v, i} & \text { Design normal vertical stress of the row section } i \\ 794 & \sigma_{d, h, i} & \text { Design normal horizontal stress of the row section } i \\ 795 & \sigma_{v} & \text { Normal vertical stress } \\ 796 & \sigma_{h} & \text { Normal horizontal stress } \\ 797 & \sigma_{e x t} & \text { Normal Stress on outer line } \\ 798 & \sigma_{\theta} & \text { Hoop stress } \\ 799 & \sigma_{\theta, c} & \text { Hoop compression stress } \\ 800 & \sigma_{\theta, t} & \text { Hoop traction stress } \\ 801 & \tau & \text { Shear stress } \\ 802 & \mu_{b a g s} & \text { Friction coefficient of the contact between bags } \\ 803 & v & \text { Poisson coefficient } \alpha\end{array}$

